\title{
Religion and Integration: Issues from International Literature
}

\author{
Annavittoria Sarli and Giulia Mezzetti
}

The available literature on the relationship between migration and integration can be divided in two research strands that are based on opposite sets of assumptions developed mostly on the two sides of the Atlantic, namely in Western Europe and North America (Alba, Foner, 2015; Kivisto, 2014; Lewis, Kashyap, 2013; García-Muñoz, Neuman, 2012; Zolberg, Woon, 1999).

The North American literature on migration - particularly the us one- tends to see religion as a factor fostering integration, by playing a role in addressing migrants' social needs. Religious identity and participation in public religious life are thought to facilitate the Americanization of recent migrants and of their descendants, strengthen their sense of belonging vis-à-vis the host country and increase the level of acceptance of minorities by the dominant group (Foner, Alba, 2008).

On the contrary, in Europe the literature sees migrants' religion as a problem and a potential source of conflict, in line with a social attitude widespread across the continent. In particular, the relationship between religion and integration tends to be framed in a negative way as religious affiliation, especially with Islam, is considered to be a marker of wide social distance and a factor of disadvantage in the interaction with the native population (Fiddian-Qasmiyeh, Qasmiyeh, 2010).

These distinctive, opposite perspectives about the link between religion and integration derive from significant divergences in the two social and cultural contexts, which generated two different public discourses on the issue. In fact, we are here dealing with contextual discrepancies of cultural, institutional, and demographic nature (Kivisto, 2014). These differences, in turn, have produced diverging influences on social research, in terms of assumptions, of topics to be investigated, and, hence, of findings. Indeed, as Weber (1922 (2003) authoritatively pointed out, social sciences are always rooted in and produced by the culture where they unfold.

The present chapter sets to examine these contextual differences and their influence on the research questions and approaches that have animated the study of the relationship between religion and migrant integration, across the 
two sides of the pond. In $\S 1$ and $\S 2$, describing respectively the North American and the European contexts, we follow a similar structure: we start by presenting the context and institutional arrangements characterizing the two areas and we reconstruct the different public discourses that developed in the two public arenas; subsequently, we discuss how this impacted social science research on these topics. In light of the comparison outlined, in §3 we propose some conclusive reflections that put these two "traditions" into perspective by tracing recent tendencies that are actually making the two contexts more similar in their approach to migrant religion in integration processes. On the one hand, public discourse in the US started framing migrant's religion as problematic when it comes to Muslim migrants and communities; on the other hand, across European countries, both institutions (at different levels) and civil society started considering religious leaders and communities as potential allies in facilitating integration and in promoting social cohesion, thus possibly getting past the idea that religion is intrinsically an obstacle to integration. This, in turn, may open further directions for research.

\section{Religion and Integration in North American Social Sciences}

\subsection{Salient Contextual Factors}

In North America, and particularly in the US, social sciences tend to describe religion in positive terms, as a major facilitator of integration and a source for overcoming social exclusion. This view has been crucially influenced by a series of historical processes.

In the US, the institutionalization of religion took place on the basis of the religious diversity featured among colonies and then States. Such a diversity made it impossible to create a single "State Church" in the newly-formed federal State. This has led to constitutional fundamentals being codified to enshrine essential principles such as religious freedom, substantial equality among all faiths, neutrality or equidistance between the State and all confessions, with a clear separation between Church and State. Kuru (2009:11) defines this institutional setting as "passive secularism", whereby such a neutrality on the State's side allows for the public visibility of each religion. Undeniably, until the end of the Second World War, the Catholic and Jewish minorities enjoyed little acceptance among the Protestant majority and were forced to relegate their religion to the private sphere. However, such an institutional framework has allowed religious groups to put forward religiously-based demands, which have become a common feature of American life, laying the 
foundations for a multi-religious nation from the very beginning (Foner, Alba, 2008). Based on these assumptions, by the mid-19oos Jews and Catholics could be integrated into the American pluralistic system. This process has shaped the religious pluralism that many migrants with different religious backgrounds still experience once they move to the US-including the more recently settled Muslim minority, whose incorporation in the American religious landscape presents significant differences as compared to Europe.

Indeed, the evolution of religious pluralism in the US must be seen in the context of the nation-building process. Since its creation, the US have labelled itself as a country of immigration, and have made migration a founding myth underpinning its national identity. As a result, the permanent settlement and naturalization of migrants tended to be promoted, which facilitated both the migration and the integration process at the earliest stage by strengthening migrants' emotional bond with the receiving society. While the country has promoted the "Americanization" of newcomers, it has also recognized the legitimacy of multiple identities - the so-called "hyphenated identities". Religious identity has therefore often been perceived as a distinctive feature to be combined with a common sense of belonging to the American nation, thus playing a key role in the incorporation of migrants into the dominant society (Papademetriou et al., 2016; Alba, Foner, 2015).

The passive secularism (Kuru, 2009) featuring Church-State relations in the US is at the basis of the central role played by religion in integration dynamics. According to this setting, the State allows the public visibility of religion. This has been conducive of a positive view of religion, generally conceived as a civic value and highly acknowledged in the public sphere. Even if in the US religiosity has been declining over successive cohorts (Voas, Chaves, 2016), in the US religiosity tends to be exhibited and being religious is considered as the social norm: surveys concerning religious beliefs and services attendance demonstrate high levels of religiosity among Americans (e.g. PEW, 2011; Gallup, 2009). As Alba and Foner note (2015), Americans tend to overstate their church attendance and degree of religious practice; however, this very tendency testifies to the perceived importance attributed to religion on the American public ethos. Hence, the religious engagement of migrants ends up favoring their social inclusion (Kivisto, 2014; Niebuhr, 2007).

This is the institutional and socio-cultural environment where North American social scientists have conceived their research questions, and the ground they have explored to formulate their research outcomes. It is easily conceivable that, within this framework, religion has generally been observed as a source for integration and research has investigated how this facilitating role is played. 
There are also demographic contextual factors that account for this tendency in North American social sciences: in the US, the majority of migrants identify as Christians, a feature that is in line with the one of the dominant society. Therefore, viewing religion as a catalyst of integration has been favored by the perceived "low" religious distance between natives and migrants. On the other hand, the predominantly Christian group of Mexican migrants face serious integration issues (Papademetriou, 2016; García-Muñoz, Neuman, 2012). Subsequently, in the American context, the main dividing line marking social distance between native and migrants tends to be language and cultural belonging (Zolberg, Woon, 1999). On the contrary, religion and religiosity are generally seen as a potential bridge between different ethnic groups and this common perception is mirrored in the approaches adopted by social researchers.

Nonetheless, even such a "religion-friendly" context has not been immune to the expression of concerns towards religions that are depicted as more "distant" - and particularly towards Islam, which has been framed as the "enemy of the West". In the US, a negative construction of Islam had been taking place in the immediate post-Cold War era, when Islam started being cast as the new threat for Western powers: indeed, Huntington's theses (1993) about the existence of a "clash of civilizations" between the West and Islam have been gaining currency in most public debates worldwide (Nielsen, 2013). This could not but be reinforced by the $9 / 11$ events and by the following string of jihadist attacks perpetrated in Western countries. However, paradoxically, for a long time such concerns have only marginally regarded Muslim migrants living in the US. In fact, they could benefit from the institutional arrangements that favor the accommodation of new religions (Alba, Foner, 2015). This has also been facilitated by the fact that they constitute a small minority and that, contrary to the majority of Christian migrants, they have reached a high degree of socioeconomic integration, with levels of education even higher than the national average. Rather, the perception of threat has long been imputed to Islam as an external enemy within the realm of international relations, which led to frame this religion in securitarian terms (Foner, Alba, 2008; Frisina, 2010).

However, as we will discuss in the final section of the present chapter, recent analyses have highlighted how this tendency is taking on a more culturalist flavor, with Islam -and more precisely American Muslims- being subjected to forms of cultural racism, which parallel similar, more rooted attitudes that characterize the European context more profoundly. This does not mean that manifestations of this type of racism were completely absent in the American context in the past decades; however, they concerned fringes of American society (Council on American-Islamic Relations, 2016). How this has become a more mainstreamed trend will be discussed in $\S 3$. 


\subsection{Religion as a Catalyst of Integration in US Social Sciences}

In the preceding pages, we have analyzed the socio-cultural and demographic features that have generated, within US society, positive perceptions of migrants' religious belongings and their function for social cohesion. As has already been hinted at, this orientation in collective representations and public discourse has undoubtedly played an influential role in shaping the assumptions and perspectives of social researchers in exploring the link between religion and integration. Indeed, the view of religion as a resource in integration dynamics can already be traced in classics of the American literature on migrants' religious life, such as the contributions by Herberg (1960) and Handlin (1951) that highlight the particular role religion played in the assimilation of Catholic Europeans and Jews who had come to the US -a predominantly protestant society- after World War II. In this regard, Herberg (1960) observes that having found greater social acceptance of religious diversity, rather than ethnic diversity, these migrants saw the religious sphere as a privileged space for the construction of their own American identity (Herberg, 1960).

Gordon (1964) and Smith (1978) reiterate this consideration by noting that the religious connotation of migrants' identity allows them to maintain their cultural specificity while blurring their ethnic and national differences. As a component that is not necessarily linked to a specific place, religious identification offers the possibility to settle in a new territory without losing ties with one's origins and traditions. Kurien's "Becoming American by becoming Hindu" (1998) illustrates this idea very clearly, as it presents the mechanism by which Indian migrants leverage on their Hindu identity, or rather its updated version, resulting from the adaptation to the new context, to claim their position within the American pluralistic society, while maintaining ties with the Hindu tradition. Similarly, Ebaugh and Chafetz (2000) define religious institutions as physical and social spaces where the adaptation to the new environment can develop along with the cultural continuity needed by migrants.

This approach to religion, which took shape at the time when Judaism and Catholicism were being embedded into the US pluralistic system, has characterized all relevant North American literature, and continued to permeate US social sciences, even after new waves of migration from non-European countries have greatly expanded the religious diversity of the American society, especially since the Immigration and Naturalization Services Act was passed in 1965 (Portes, Rumbaut, 2006; Casanova, Zolberg, 2002; Warner, 2000a, 200ob).

Thus, drawing on this scientific tradition, which mirrored a "religion-friendly" social and cultural context, North American social scientists have been tending to observe religion as a source of tangible and intangible assets - a "spiritual capital" that promotes the integration of migrants (Hagan, 2008; Stark, 
Finke, 2000). As we will see, most of their investigations on the link between religion and integration aim at exploring the various components of this "spiritual capital", shedding light on their function in favoring integration dynamics, with reference to several domains of social life.

As thoroughly explained in Chapter 17 , individual and collective identities are process-based and multi-dimensional, as they are constantly re-shaped according to the historical and social context, and are composed of multiple aspects that are more or less coherent with each other (Ajrouch, 2004). The very process of migrating produces deep changes in the migrant's socio-cultural context of reference, thereby generating the migrant's need to redefine oneself in relation to the new environment. North American literature widely shows how religion can provide valuable tools in this sense (Talebi, Desjardins, 2012), both for maintaining one's own identity in the new context of emigration, and for adapting to such a new context, even across different generations.

US scholars observe that, when building their identity, migrants draw on their religious sphere by activating several mechanisms. For instance, religious organizations are used to replicate major aspects of the culture of origin in order to keep the ethnic identity alive and pass it on to second generations. As a result, different aspects of the culture of origin are often incorporated into religious ceremonies. For example, rituals can be performed in the language of the place of origin and be accompanied by traditional music (Ebaugh, 2010; Foner, Alba, 2008; Carnes, 2004; Ebaugh, Chafetz, 2000; Warner, Wittner, 1998; Min, 1992).

Min's work (2005) shows, for example, how groups of Hindu Indians and Christian Koreans preserve their ethnic traditions by overlapping and combining ethnic and religious rituals together. With reference to second generations of Christian Koreans born in the US, Chai (1998) illustrates that religious organizations contribute to the reproduction of ethnic identity through the sacralization of traditional values. In other words, people reinterpret their traditional culture in the light of the values of a conservative Christian morality.

Another aspect of religion that was studied by North American scholars in connection with identity construction is religious conversion. The latter are an increasingly frequent phenomenon - in general terms and not only among migrants, in a cultural context that is characterized by a growing subjectivism in religious orientations (as illustrated in depth in Chapter 3 of the present volume). Conversion has been conceptualized as the adoption of an identity that has been chosen independently and consciously for its role in responding to existential needs (Hervieu-Léger, 2003). Several studies on migrant conversions in the US highlight that people's agency plays a crucial role in shaping new religious identities and in combining them with other aspects of identity, 
such as the ethnic or national one (Ebaugh, 2010). For instance, in exploring the reality of some Chinese Churches in the US, $\mathrm{Ng}$ (2002) notes that, by converting to Christianity, these migrants bring with them their own cultural categories, their own symbols and their own practices, which are all incorporated into a religiosity that is both a distinctive trait of a minority culture and a trait shared with the dominant society. In focusing on a similar context, Yang (1999, 2000) shows that conversions drive people to renegotiate the very meaning of "belonging". By redefining what being Chinese, American and Christian means and by identifying and combining the elements of each of these multiple identities that are most functional to the new context, migrants perform selective processes in both assimilating to the host society and preserving ethnicity.

Smith-Hefner (1994) also notes that, among Cambodian Khmer refugees in the US, the conversion to Christianity addresses the need to abandon the previous identity and acquire a new one, thus leaving the pain, the grief and the guilt experienced behind. At the same time, however, Smith-Hefner highlights a further function: conversion offers opportunities for social mobility, by enabling people to access positions of authority and prestige within religious organizations. Several authors stress that religious participation can address the need to build a positive social identity. The roles available within religious communities allow migrants to obtain the social recognition that is denied in the hosting community. Both on a personal level and in the eyes of members of the religious group, the position reached through religious practice enables people to cope with the sense of subordination experienced in emigration, namely in the social and occupational sphere (Warner, 2000). Smith-Hefner (1994) takes the analysis of the functions of religious conversion among Khmer refugees even further. According to the author, by becoming Christian, many young Khmers get involved in activities and organizations that socialize them to a new system of values. As a result, by distancing themselves from their own tradition, they have the possibility to reduce the barriers that separate them from the mainstream American society. Hirschman (2004) has efficaciously synthesized the workings of these processes by arguing that religious organizations in the US provide immigrants with psychological solace from discrimination, hostility and, in general, from the traumatic experience of emigrating (refuge), access to opportunities for economic mobility (resources) as well as social recognition (respectability).

So far, the analysis has focused on how some of these resources are activated through an identity building that is able to provide migrants with value systems, relationships and opportunities for social mobility. Religion, however, can also mediate other adaptive processes, as it represents a cultural institution that helps humans make sense of everyday life and of the challenges it 
poses (Bankston, 1997). Religious involvement and practice constitute an individual and collective process that can enable the maintenance of emotional balance. This is particularly true in situations of trauma or stress, both factors being often associated with the migration experience. For this reason, several US authors underline the importance of the spiritual resources made available by religions and underline their positive psychological effects on migrants' ability to cope with uncertainty and difficulties (Kyoung Ok, Lee, 2012; Connor, 2012; Suárez-Orozco et al., 2012).

These resources consist first of all of the consolidated and rich symbolic heritage that people can draw from to give sense to the pain experienced in the process of migration (detachment from motherland, orientation in a new context, racism...). Religious organizations often support people in these processes of creation of meaning through a set of activities that Schiffauer (2006) defines as spiritual welfare, ranging from purification exercises to spiritual assistance. Furthermore, through these organizations, migrants can build social networks that provide them with psychological support in times of hardship.

By analyzing data on the mental health of migrants in Australia, the US and Western Europe, Connor (2012) notes a positive correlation between regular participation in religious activities and emotional well-being in the three contexts. According to his analysis, a close relationship between religion and migrants' inner balance exists independently of the contextual elements, which leads the author to suggest that this aspect be taken into account when designing integration policies, as involvement in religious organizations appears to be more effective than participation in other types of ethnic associations.

In the case of migrants who have escaped from situations of mass violence, persecution, war or natural disaster, the comforting power of faith is often crucial. Religious values and rituals, indeed, provide a sense of peace and inner salvation (Fox, 2012). Populations that have lost their original geographical bound and that are now scattered across regions can regroup around religious organizations. The latter help them activate social practices that, in turn, give a new meaning to people's life (Talebi, Desjardins, 2012; Zhou et al., 2002).

While spiritual capital encompasses a series of intangible resources, such as the strength of faith and its "curative" power, North American literature also highlights a series of tangible advantages that, for the most part, are accessible through participation in religious organizations. Religious organizations offer tools to overcome the initial hardship of integration and draw a path of upwards social mobility over time. They promote social support services and, thanks to the trust established among fellow believers, they facilitate the flow of information on housing, education, entrepreneurship or employment 
opportunities (Cadge et al., 2013; Munshi, 2003; Guest, 2003; Campion, 2003; Ebaugh, Pipes, 2001; Menjivar, 2001; Bankston, Zhou, 2000). In some cases, religious institutions become a source of information and social support even for migrants with different religious affiliations. For instance, in some contexts, the Church plays a crucial role in promoting migrants' rights, as well as their political and social inclusion, thanks to its transnational presence and the activism of its members (Kim, 2011).

Several US researchers see religious communities of migrants as places where second generations can acquire the social and cultural capital needed to succeed at school and get a sound position in the receiving society (Ebaugh, 2010; Bankston, Zhou, 1996; 1995). In some cases, they do so by organizing educational activities, such as language courses, to maintain the language of origin and learn about the language of the hosting country (Lopez, 2009). In other cases, they run private schools that second generations see as an important opportunity for social mobility (Smith-Hefner, 1994). Several North American authors underline the protective role played by religious organizations vis-à-vis migrant children. By promoting various recreational and educational activities for children while their parents are working, they often manage to prevent them from falling in deviance (Foner, Alba, 2008; Zhou, Bankston, 1998). For all these reasons, Cao (2005) and Guest (2003) describe religious communities as places where second generations can find social, financial and parental support.

In addition, many US scholars describe how religious groups provide migrants with a first opportunity to learn about participatory democracy (Foley, Hoge, 2007; Eck, 2001). Through religious activism, migrants have the opportunity to take part in elections and steering committees or learn how to chair meetings and organize public events (Foner, Alba, 2008). Religious institutions often encourage volunteering, also by opening it up to people of other faiths (Ecklund, 2006; Ebaugh, Pipes, 2001; Ebaugh, Chafetz, 2000; Wuthnow, 1999; Cnaan, 1997; Min, 1992).

North American literature widely shows that religion may become a resource for engaging migrants civically, but also for mobilizing them politically (Kurien, 2014; Levitt, 2008; Ecklund, 2006; Ramakrishnan, Viramontes, 2006; Lien, 2004; Menjivar, 2003; Chen, 2002; Kurien, 2001). Some religious groups promote courses on active citizenship, support citizenship programs and encourage the participation of naturalized migrants in elections (Ebaugh, Chafetz, 2000; Min, 1992).

Some US authors highlight that different religious ideologies have a different influence on how organizations support migrants' civic engagement and political participation. Chen (2002), for example, shows that a Buddhist temple 
and an evangelical organization, both run by Taiwanese migrants, can have very different approaches to civic engagement, with the Buddhist temple tending to promote the organization of charity activities for the community with greater intensity than the Evangelical Church. One of the main reasons motivating this difference lies in the more heightened perception of "foreignness" associated to Buddhist immigrants, who feel pressured to prove their "Americanness" through acts of public relations more than Christian immigrants do.

As illustrated by some North American scholars, religion can also have an important impact on how naturalized migrants are positioned in the political landscape of the hosting country, by encouraging new ideological alliances. Ethnic and religious identity often determines what forms these political coalitions take (Ebaugh, 2010; Lien, 2004; Leal et al., 2005; Espinosa et al., 2003). The country of origin sometimes has an influence on the political life of the hosting country through migrants' transnational relations within the religious domain (Levitt, 2002). Moreover, religion can lay the foundations for global citizenship by encouraging forms of transnational activism, for example on themes such as education, work and health (Levitt, 2008).

This literature review testifies to the multifarious perspectives in which religion has been described as a facilitator of integration by social scientists in the North American context, in line with research questions and designs that intentionally set to explore the role of religion as a resource in the process of settlement. However, as we will see in the following paragraph, the peculiarities of the European context produced a completely different perspective, which interrogates the relationship between religion and integration in opposite terms, as it frames religion as an obstacle for the incorporation of newcomers, rather than as a potential resource.

\section{Research on the Religion and Integration Nexus in Western Europe}

2.1

\section{The European Context: Secularization, State-Church Relations and} the Public Discourse about Migrants' Religion

While the cultural landscape of the US allows for a more generalized acceptance of religion, some core and deeply entrenched traits of Western Europe's cultural, social and political identity make it impossible to view religion as a facilitator of migrants' integration processes, which cause an extremely different consideration and treatment of religion as compared to the US. These core features result from two main historical developments: on the one hand, "secularization" and the continuously diminishing levels of religiosity of Western European populations; on the other hand, long-established institutional 
arrangements governing State-Church relationships, which make the enjoyment of religious rights almost exclusive for "old", mainstream religions. As divergent and unrelated as they may seem, these two tendencies are strongly intertwined: in fact, scholars in this field widely agree in tracing both of them to the Peace of Westphalia (1648) and its effects.

That Treaty put an end to bloody and violent conflicts between and within Protestant and Catholic reigns by sanctioning that the religion of a territory would be that of its ruler. That had considerable consequences in two directions. First, it established an official, direct linkage between modern European States and their respective rulers' religion, thereby creating the ground for establishing a State Church. Second, it identified a clear condition for the maintenance of peace - that is, the expunction of religion from public and political affairs, as religion, from that moment on, was not to be made a matter of contention or a reason for waging war between and within States. This paved the way for a gradual "banning" of religion from what we now define "the public sphere": the issue lied not so much in religion qua talis; rather, it was represented by its public dimension and manifestation, with its possible consequences at the geo-political level (May et al., 2014). Religion was then gradually confined to the private sphere: faith was assigned a limited -and limitingspace. As explained by Introini (2017), this meant positing the very possibility to distinguish between what is private and public in religion, by judging the latter as particularly dangerous for social order. Therefore, while establishing almost exclusive relations with one main confession, the State "obliged" religious institutions to recognize that there were two separate entities: the State, having the monopoly over the management of political affairs, and the Church, that ought to deal only with religious affairs, within the space delimited by the State. These institutional arrangements regulating the "boundaries" of religion are therefore co-essential with the genesis of the modern nation State, based as it is upon the "taming" of religion. This is the reason why the Peace of Westphalia sowed the seeds of secularism, as primarily understood as an intentional separation between "the political" and "the religious".

Today, we can distinguish the consequences and implications of these historical developments for our object of study in two main domains. Firstly, the institutional settlements regulating the presence of the "nation's" Church in every European nation-State entailed that there would be no -or very limitedreligious pluralism within each of them (Kivisto, 2014). Contrary to the US, where no single state Church could (and can) be established, allowing for a gradual pluralization of the religious landscape, every European nation-State would accord special privileges to the Church (be it Protestant or Catholic), which entailed a substantial religious homogeneity in each of them, with one 
dominant, prevailing confession. These privileges seem to be unattainable by the "new" religions brought by newcomers - which accounts for substantial inequalities in the possibility to enjoy religious rights. For instance, representatives of migrant religious communities may find it practically impossible to obtain funds to construct places of worship, or to establish religious schools, across Western European countries, or had (and still have) to go through very lengthy processes for being acknowledged as interlocutors by local and national-level authorities (Laurence, 2012; Joppke, Torpey, 2013; Alba, Foner, 2015). The reluctance of European States to accommodate migrants' religions institutionally -and to acknowledge the religious plurality now characterizing their societies-is linked to the peculiar economism that has traditionally been marking the European migration regime. By importing manpower in the form of "temporary migrants" or of "guest workers" in the post-war decades, Western European countries have followed a model by which migrants' presence was conceived as purely momentary, aimed as it was at filling labor market's contingent demand for work force. In such a perspective, migrants have been viewed only as workers, which entailed a long disregard for the social, cultural and religious components of their identities - and a consequent institutional neglect of these aspects in the process of migrants' incorporation (Zanfrini, 2019). Although this model typically characterized post-war immigration, its effects are still persistent, as the example of States' (absent or belated) recognition of religious pluralism clearly shows.

Secondly, and even more importantly, political secularism (separation between Church and State, and erasure of the Church from political affairs) stimulated cultural secularism (gradual diminution of personal levels of religiosity among individuals). According to May et al. (2014), the division between the political and the religious, superimposed on the distinction between the public and the private, entailed that less and less value would be attributed to the religious, because the public/political was considered to be much more important (Introini, 2017). In other words, the progressive devitalization of the public dimension of religion (necessary to contain its potential as a source of conflicts) caused a progressive loss in importance of religion even in the private sphere. Incidentally, this would lead to consider those faiths in which the believer is encouraged to cultivate an extremely privatized practice (read, the Protestant confessions) as better compatible with the public ethos - something that affects the way research is conducted in this domain, as we will see below.

This process was also significantly reinforced by the diffusion of Illuminist ideals, whose trust in the human's reason and rationalism would free men from the obscurantist conditionings of tradition and superstition - and, ultimately, 
of religion. Countless sociological accounts explain how the European experience of the "project of modernity" is co-essential with the process of secularization. Admittedly, contemporary Europe is characterized by a coexistence of secularized attitudes and different forms of religious beliefs and practices (see Chapter 3), whose vitality is also meaningfully linked to the cultural transformations generated by globalization and migration. Therefore, while religion has all but disappeared, neither in public life nor in private lives (Pollack, Rosta, 2017), factual evidence points to a prevailing decline in "traditional" religious attendance and behaviors (Hunt, 2005). Indeed, for the majority of Western Europeans, it is commonsensical to represent themselves as non-religious, with religious symbols of major, traditional denominations simply being perceived as elements of the cultural heritage. Surveys well illustrate this trend: according to a PEW study (2018), only $22 \%$ of interviewed Western European Christians declared to attend a place of worship regularly. Only a fifth -or lessof the population of France, Germany, the United Kingdom and the Netherlands would affirm that religion is very important in their lives, as reported by another survey conducted by PEW (2011).

In light of the above-described cultural setting, it is not surprising that Europeans tend to view religion as the most problematic aspect of immigrant integration. In nations characterized by religious uniformity (rather than by the coexistence of different faiths as in the US), and by increasingly marked secularist attitudes, public discourses across European countries inevitably fixated on migrants' religiosity and degree of practice of religion as the most prominent "features" incarnating the "difference" between receiving societies and migrants, ascribing to religion all of what most distinguishes Europeans from "the Other". As Alba and Foner (2015) point out, immigrant religion in Europe has become a significant marker of social divide and a source of conflict as "race" is in the context of the US. In recurrent debates about migrationrelated anxieties, the religious affiliation of immigrant populations has come to represent a dividing line to the extent that it is deemed the main obstacle in their process of integration.

However, it is safe to affirm that this does not refer to "any" religious affiliation, as these tensions concern most exclusively Islam. Indeed, as many scholars have amply demonstrated (e.g. Césari, 2004, 2013; Modood et al., 2006; Massari, 2006; Bowen, 2007; Celermajer, 2007; Foner, Alba, 2008; Fredette, 2014; Beaman, 2017; Alba, Foner, 2015; Bowen et al., 2015; Pickel, 2018) Western societies, and particularly European ones, have developed a terribly fraught relationship with Muslims migrants and the practice of Islam over the past decades. The reason why this is the case partly lies in the fact that Muslims constitute (and will continue to constitute) a large part of the overall population with an 
immigrant background in Western Europe ${ }^{1}$-much more, both in relative and absolute terms, than in the US, where immigrants are mostly Christians (PEW, 2012) - as anticipated above. In other words, whilst the population of migrant heritage in the US presents high degrees of diversification in terms of ethnicities and migratory backgrounds, in various European countries migrant populations mostly originate from Muslim-majority countries. In fact, other non-Western religions (Buddhism, Hinduism, etc.) represent extremely low percentages of the immigrant population residing in European countries (ibid.). This facilitated the perception of Muslims as quite a "neat" bloc of "foreigners", and gradually induced an automatic association between "immigrant" and "Muslim" (Allievi, 2005; Brubaker, 2013).

A significant factor that motivated the singling out of immigrants with a Muslim background or affiliation as a distinctive "socially distant" group is their socioeconomic profile, which is quite low in all European countries (Césari, 2011; Zanfrini, 2019). For the most part, when they started settling in Europe, they had poor levels of education and were employed in jobs at the bottom of the labor market; after decades since their settlement, relatively high levels of unemployment have affected these groups and patterns of inequality and of socio-economic disadvantage still significantly concern their Europeborn descendants; lastly, they often find themselves segregated in deprived neighborhoods and housing conditions.

However, this perception of "distance" with "Muslims" is not just based on demographic characteristics. Actually, it results from a tendency to view Muslims, in "Orientalistic" terms, as the enemy of the West, which is rooted in centuries-long confrontations, form Crusades to colonialism, as described by Said (1978). More recently, a "revival" of this process of "Otherization" took place in the context of the gradual settlement and visibilization of Muslim migrants in European societies during the second half of the 2oth century. This further reinforced a constructed image of Islam in negative and oppositional terms as the "West's Other" - an image that, by now, has become deeply ingrained in European countries' public opinions. The first patent manifestations of this uneasy relation with migrants' Islam date back to the late 1980 ,

1 According to the data collected by PEW (2012), the share of immigrants coming from Muslimmajority countries and the share of Christian immigrants are very close, as the former account for $39 \%$ of the total immigrant population residing in the European Union, while the latter represent $42 \%$ (these figures refer only to immigrants from non-EU countries). On the contrary, in the US, Christian immigrants ( $74 \%$ of the total immigrant population) largely outnumber Muslim immigrants ( $5 \%$ of the total immigrant population). 
when the polemics aroused by the "Rushdie affair" 2 in the UK and by the affaire $d u$ foulard $^{3}$ in France marked the beginning of heated and enduring controversies that brought to light the gradual rooting of Islam in European countries.

In the public debates that ensued these two sets of incidents, the behavior of the Muslim immigrant population was deemed to be challenging core "Western" values: in particular, freedom of speech, gender equality (with the veil being considered as a sign of oppression towards women), and the separation between State and religion, allegedly threatened by the request of a separate regime of religious rights. Therefore, these events seemed to question the very nature and narrative of secular States and of secular societies (Nielsen, 2013:168). In this sense, they paved the way for an increasingly distrustful depiction of Muslims, who have been regarded with suspicion as potentially nonintegrable citizens ever since.

Similar discussions surrounding Muslims repeatedly take place in other European countries. ${ }^{4}$ In addition, the centuries-old, exclusive systems of ChurchState relations existing in all European countries made it quite impossible for a new religious group, such as Muslims, to be treated on an equal par with mainstream religion, meaning that the accommodation of their religious demands have always been objects of heated contentions, as illustrated above. In fact, a malaise in accepting the increasing diversification of societies concretely manifests itself in controversies over those symbols that would definitively mark the presence of Islam in the European cultural landscape - as testified by the numerous recurring local conflicts over the establishment of mosques

2 Muslim leaders, communities and organizations organized demonstrations across Britain but also in India and Pakistan-in response to the publication of Salman Rushdie's novel "The satanic verses" by a British publisher, as the book was considered blasphemous and offensive towards Muslims. Some of these protests culminated with the burning of the book, a violent action bearing a strong symbolism, which sparked harsh criticism. The polemic and the spiral of reactions and counter-reactions reached their peak when ayatollah Khomeini of Iran issued a fatwa ordering Muslims to kill Rushdie.

3 In this case, the controversy evolved around the gradual refusal of some headmasters to accommodate the demand of some female Muslim teenagers to wear their hijab in public schools, with the explanation that this would allegedly endanger the principle of laïcité of the State.

4 Specious controversies about the respective limits of freedom of speech and minorities' rights aroused again in Denmark, with the publication of a series of cartoons featuring the Prophet Muhammad on the newspaper "Jyllands-Posten" and the following protests that took place in many countries across the world. Debates on an alleged intrinsic impossibility of gender equality in Islam recur, especially when a country considers the possibility to ban partially or completely- the full veil, or niqab (Belgium, France, Denmark, Germany, and the Netherlands). A constantly updated review of the issues and the debates about Islam in Europe is available on the website www.euro-islam.info. 
(Allievi, 2009) or by the emblematic Swiss ban on minarets voted through a referendum in 2009 .

More generally, the point of departure of debates on these issues is the superiority of the West's "secular normality", on the basis of which migrants from Muslim-majority countries are assigned an a priori negative, "Muslim" identity, as if they constituted a threatening, monolithic and undifferentiated Other by virtue of their "problematic" religion - something which makes them radically different than the "secular us" (Jeldtoft, 2013:26-27). As a result, any debate about the integration of Muslim immigrant populations in Europe is framed in culturalist terms (Frisina, 2010; Césari, 2011), as will be developed below. All negative trends in this domain are easily attributed to Muslims' alleged lack of will to integrate, due to their backward religion, which, because of its very tenets, would make Muslims "disloyal citizens", intrinsically incapable of ever being "truly" modern or European (Kivisto, 2014). For example, where Muslims are ghettoized and concentrate in urban, peripheral and more disadvantaged areas, Islam is perceived as responsible for their "failed" integration and their presumed desire to live "parallel lives", separate from and in opposition to the rest of society. ${ }^{5}$ Or, jihadist radicalization of disenfranchised youths was explained only with their belonging to Muslim "enclaves" at the margins of society: while it is true that religious movements such as Salafism are on the rise in Europe, and especially in poor, more deprived areas (although this phenomenon remains strongly minoritarian in absolute terms), the debate tends to exaggerate or generalize towards all Muslims these mistrustful depictions.

\subsection{Migrants' Religion - and Islam- in European Social Sciences}

Having analyzed the general consideration of religion in the European context, as well as today's public discourse about immigrant religion -i.e. Islam- we can now examine how social scientists approached the study of religion in migrant integration processes in Europe.

Concerning the topic of religion in general, we may affirm that social sciences have not been quite neutral, as they contributed to and enthusiastically espoused the cause of secularization since the very beginning: the triumph of

5 In the case of French banlieues, even events that were not connected to religious demands have been tellingly interpreted under the prism of Islam: the riots that took place in the peripheries of French cities during autumn 2005 were initially linked to a supposed "Muslim rage". While the riots certainly channelled rage at and contestation against discriminatory institutions, they did not express any demand concerning Islam or religion: actually, they represented a massive demand for citizenship, recognition and inclusion (Kepel, 2012; see also the special issue of the Journal of Ethnic and Migration Studies, n. 5. vol. 35, 2009 entirely devoted to this topic). 
"science" over "superstitious beliefs" was seen as key in global the emancipative project of rationalization and modernization (Introini, 2017; Chapter 3 in the present volume). This means that any investigation of "the religious" in Europe is framed within the hermeneutic "principle" of secularization, with a "secularist bias" affecting the study of these topics.

This had a first fundamental consequence: social sciences in Western Europe have been much less "sensitive" to treating religious matters and much more incapable to grasp their many shades. This obviously impacted the study of migrants' religion, as such a secularist bias caused a "structural" blindness in research assumptions (Introini, 2017; Kivisto, 2014), whereby the potential of religion for integration, or its role as facilitator of the process of incorporation into receiving societies are hardly taken as research questions, almost taking for granted that it represents a stumbling block.

A subtle -but highly significant-impact of the "secularist bias" is illustrated, for instance, by how research about the religiosity of Muslim migrants and of their descendants in Europe has tended to study religiosity through the prism of an often-wished-for privatization (Mahmood, 2005; Barylo, 2017; Introini, 2017; Celermajer, 2007). In other words, there has been a tendency to test whether trends of "protestantization" were in place among religious migrants, starting from a viewpoint that looks at the extent to which the West has been able to "tame" religion and Islam (Sunier, 2014). However, when it comes to Islam, this approach appears profoundly inappropriate and unfruitful. Indeed, the study of Islam seems all the more to challenge the conceptual framework with which the West and social sciences have "domesticated" the religious sphere, because its orthodoxy, belief system and trajectory cannot be assimilated to that of Christian traditions, meaning that distinctions between private and public, religious and non-religious do not work in the same way for Islam as they do for Christian denominations. Therefore, while these studies were important in sketching some significant issues and trends, they nonetheless run the risk of offering an incomplete picture of Muslims' relation to religion and self-identifications -one that wittingly or unwittingly tends to consider Muslims as "misfits" whose "incomprehensible" religiousness deviates from the West's (supposed) secular normality. For instance, Sunier (2014) argues that surveys conducted among people of Muslim affiliation in Europe on identity and religiosity suffer the problem that they mainly aim at showing that Muslims, despite their religion, become integrated -read, are assimilating- to presumed homogenous and "superior" Western cultures and values. To put it differently: even with the best of intentions, these studies are designed to address the question of whether Muslims' integration into society proceeds thus, always from the standpoint of Islam's “domestication". 
However, it is not just a secularist bias that impedes to formulate research questions aiming to investigate the potential resources offered by religion for integration. Indeed, the way migrants' religion was framed and studied inevitably reflected the above-described negative dominant discourse about Islam. It is true that studies which deconstruct negative prejudices and stereotypes concerning migrants' religion and particularly Islam abound in scientific literature. Indeed, as documented by Nielsen (2013) and Jeldtoft (2013), the life of Muslims and of their descendants in the West has come to represent a compelling object of study. In the past three decades, a consistent quantity of research has been conducted across European countries, enquiring about the actual conditions of Muslim immigrants, the levels of discrimination they endure, the accommodation of Islam in State's institutions, the significance of religion and its social consequences, the positioning and the discourse of Islamic religious actors, and the like. These research endeavors did contribute to dismantle the Hungtinonian view of Islam as an immutable, incommensurable and problematic religion. Nonetheless, there remain issues concerning the hermeneutic premises of these studies, not only because, to a lesser or greater extent, they are marked by the above-described secularist bias, but also as they partly mirror the anxieties and fixations of public discourses on this topic: it is precisely because the assumptions and starting points of these studies aim at deconstructing the negative stereotypes of public discourses, that they have the unintentional consequence of contributing to legitimize such negative images.

There is nothing strange or wrong in the fact that researchers have busied themselves with issues circulating in public debates - it is precisely the duty of social sciences to explore societal questions. However, there should also be awareness of the contexts that shape and inform epistemologies, determining research questions and who, and how, is to be investigated.

There are some overt examples of how public debates have influenced how research has been designed and conducted, possibly generating questionable results. Césari (2013: 29-39) denounces how, in many surveys, the religiosity of "Muslims" is compared to that of an undifferentiated group clustering all "nonMuslims", as the latter were homogenous. Not only does this reiterates an ideological bias by which Muslims are depicted as "something different" than "us", but is also poorly informative: Muslims should be compared to other religious groups, i.e. people who practice religion, not to "non-Muslims", who may also include non-religious people.

Other examples are represented by studies which isolate the investigated group on the basis of its religious -Muslim- affiliation, thus running the serious risk of adopting an "ethnic" or a "cultural lens", and, therefore, of offering a culturalist reading of how they fare in their process of integration into the 
receiving society (Thomson, Crul, 2007). It is certainly true that many Muslims do encounter disadvantage and marginalization; however, these should be primarily studied as problems pertaining to class, social stratification, access to education:

the social processes governing the socio-economic status of populations of immigrant origin, for example, have more to do with the social origins of migrant populations and the dynamics of labor markets, schools, neighborhoods than with religion. (...) Grouping populations of immigrant origin under a religious rubric in studies of urban marginality is (...) potentially distracting and possibly misleading; it risks suggesting a cultural explanation for a primarily socio-economic phenomenon. (Brubaker, 2013:5)

A further example concerns the way in which scholars, too, have contributed to the social construction of the meaning of the term "Muslim": "researchers have adopted the focus on Islam across ethnonational origins, ironically often because they wish to deconstruct and counter (...) crude generalizations" about, for instance, "Pakistani immigrants" in the UK or "les algériens" in France (Nielsen, 2013:170). Even if such research was precisely animated by the positive -and often attained- goal of myth-busting stereotypes about Islam as "an enemy", and considerably added to our knowledge about the condition of Muslims in the West, it is argued that it nonetheless concurred, wittingly or unwittingly, to stress the image of Islam as "something different", thus having the potential paradoxical consequence of ultimately legitimizing and reinforcing the public discourse.

This is the case of studies that focused on Muslim visibilities or on Muslim visible actors. Since "public representations (...) share an imaginary of Muslims that enhances the ways in which they are visible -vocal and involved in social conflict- to the West" (Jeldtoft, 2013:29), the majority society grants legitimacy only to those who correspond to its stereotypes and selects its Muslim "counterparts" on the grounds of their patent "Muslimness". As a consequence, Muslim actors who present themselves as "especially Muslim" in more visible ways gain a sort of monopoly, or are given a chance to impose their hegemony, in the public realm. This had important consequences also on scholarly work, as the portrayal of Muslims only as Muslims inevitably influenced the way researchers have conceptualized their object of study, with research ending up privileging visible manifestations of Muslimness as sites of observation which, again, resulted in the reinforcement of the dichotomous relationship between "us" and "them" (Jeldtoft, 2013:27). 
Indeed, just as public discourses concentrated only on more visible Muslim actors, who would frame their presence and demands in more conflictual terms, so research has over-focused on forms of Muslim life that are constructed as subordinate or antagonistic vis-à-vis the majority, and by choosing its interlocutors among visible, practicing, vocal, devout, pious, active, even militant, Muslims. As a result, countless studies concern visibilities such as the $h i-$ jab, Muslim organizations and groupings, Muslim places of worship, Muslim's claim-making and relationship with authorities, youth groups, Quran classes, transnational religious movements, and so on. Indeed, much of the existing literature has focused on organized forms of Islam, in which a substantial effort was concentrated on investigating how "these" Muslims challenge their minority status by leveraging primarily on the "Muslim component" of their identity in order to put forward demands for recognition as Muslims (to name just a few, see Mandaville, 2001; Silvestri, 2005; Klausen, 2005, 2009; Kepel, 2012; Bolognani, Statham, 2013).

Moreover, it has been underlined that research regarding young Muslims has concentrated almost exclusively on the most visible and conspicuously devout -frequently neo-orthodox- ones (Selby, 2016; Jeldtoft, 2013; Brubaker, 2013; Woodhead, 2013; Jeldtoft, 2011; Jeldtoft, Nielsen, 2011). Whilst this has been motivated by the need to "make sense" of the "sudden" -and visible- reIslamization of young western-born Muslims (Roy, 2004; Laurence, Vaisse, 2006; Kepel, 2012), who were showing to be increasingly interested in a revivalist neo-orthodox Islam (Kibria, 2008), this actually translated to a heightened focus solely on them.

Focusing on organized Muslims or on these Muslim visibilities was not only easier for scholars - as the field is more accessible when investigating identifiable, visible organizations and associations (Dessing, 2013; Schimdt, 2011). It was motivated by the fact that precisely Muslims' organizations were "attracting attention", due to their very visibility and their claim making, which was transforming Islam in a public (and sometimes political) identity. While these research endeavors sought to challenge the negative dominant discourse about Islam, at the same time they inevitably reflected such discourse, with the risk of "becoming hegemonic "evidence" of political and public understandings of Muslims as particularly (and dangerously) religious" (Schmidt, 2011:1217).

In this sense, denouncing these risks represents an invitation to an increased reflexivity in the definition of objects of study and to a heightened awareness of the never-completely-neutral role that researchers have, as any other social agent, in producing public representations. Indeed, the study of only more "visible" Muslims might end up focusing too narrowly on religion, by interpreting everything through the prism of Islam and overemphasizing the religious 
component of identities. While there are vocal Muslims who identify primarily as "Muslims" and wish to show their "Muslimness" in daily lives as their first defining feature, this might not be true for the rest of Muslims -and extending these observations to them would be artificial and simplistic. In other words, studying only visible Muslims might result in a reification of Muslims and Islam, thus falling into the pitfall of essentialization and culturalization and playing into the very hands of the dominant discourse, which portrays Muslims, in their entirety, as being "all about religion", and more importantly, their religion as an obstacle to integration.

In response to this trend in research, an opposed approach which gained ground in the relevant literature is to be welcomed, as it focuses on those Muslims who do not visibly appear as such and who escape from the discursive construction of Muslimness, which sees "Islam" as an invariable, master status and the only relevant identifier for Muslims. In seeking to counterbalance the tendency to study only the most pious and vocal Muslims, who are often found in religious organizations, this second approach has "looked for" Muslims outside religious institutions and organizations -i.e. removed from the sites of production of "visible Muslimness"- with the aim of exploring how these "non-obvious" Muslims make sense of religion in their daily lives and what meanings they attach to the practice of religion in their own right, "far" from possibly taken-for-granted (self-)representations of Islam. In response, these same researchers have pleaded for studying Muslims outside of visible or obvious Muslim visibilities (Selby, 2016; Jeldtoft, 2013; Brubaker, 2013; Woodhead, 2013; Jeldtoft, 2011; Jeldtoft, Nielsen, 2011).

Lastly, a final example of how contextual factors influenced research is represented by the broader spectrum of studies that analyze the Islamic presence in the West from the point of view of security issues. Here too, debates evolve around the role of religion as a "threat", particularly when jihadist radicalization is under scrutiny. In this case, the "secularist bias" plays out differently at the public discourse level and in research approaches. In the first case, the public discourse tends to blame the very essence of Islam for radicalization, due to its "backward" and "intrinsically violent" tenets, resorting to the Hungtinonian refrain which posits a superiority of the West's civilization over such a "barbaric religion". In the second case, the "secular lenses" explained jihadist radicalization not by resorting to religion as the "root cause", but by pointing to other factors, such as today's culture of violence (Roy, 2016) or political claims (Burgat, 2016). These have been considered extremely valid explanations; paradoxically, this research stance was precisely animated by the commendable intention to not offer culturalist explanations of this phenomenon, by not reducing it only to religion. However, this also meant that some specific religious 
shades of the phenomenon could not be grasped, which, on the contrary, need to be somehow taken into account in the analysis of the rise of jihadism in Europe (Introini, 2017; Bichi et al., 2018).

More generally, these examples show how, by foregrounding religion in our studies, social sciences may run the risk of unintentionally reinforcing negative representations about Muslims. This is why Brubaker (2013) urges scholars to exert a heightened reflexivity when approaching this object of study, in order to not consider "Islam" as a black-boxed explanans. In other words, research should not treat the categories of "Islam" and "Muslim" as tools of analysis, as this can predictably lead to use cultural lenses. Rather than as tools of analysis, "Islam" and "Muslim" should be treated as objects of analysis (ibid.). This means taking up Allievi's invitation (2005) to walk the thin line between avoiding the risk of reductionism on one hand -i.e. downplaying the importance of religion and the specificities of the religious experience- and avoiding the risk of essentialization on the other hand - i.e. overemphasizing religious and cultural aspects and explain all that concerns Muslims in light of Islam.

\section{Recent Developments and Issues at Stake in the European and North American Contexts}

As explained in the previous paragraphs, there are meaningful differences in the ways Northern America and Western Europe perceive immigrant religion. In Europe, religion has traditionally been considered a bright boundary, a central dividing line separating native from immigrants and their offspring, who, due to their religion, cannot be considered to be "like the mainstream". On the contrary, immigrant religions in the US have never represented a serious basis for contention in the same terms as in Europe - on the contrary, in many cases, immigrant religions worked as bridges rather than barriers to inclusion in the American context, as illustrated by Foner and Alba (2008), among others. As previously discussed, these diverging perceptions and attitudes have inevitably affected the way research has been conducted on both sides of the pond, with religion being considered more as a resource for integration in the North American tradition, or being problematized (and deconstructed) as an obstacle to integration in European social science.

However, we believe that some recent tendencies that have been developing in these two contexts over the most recent years have decreased the differences between them, if not enhanced possible resemblances, making them actually more similar than what it used to be the case. These trends are linked to a series of historical circumstances - particularly the jihadist attacks 
perpetrated in the US and in Europe in the past few decades, and the so-called refugee crisis reaching its peak in Europe in 2015-2016. This conclusive part addresses their role in rendering the two contexts now more akin, and sketches possible advantageous implications for future research.

\subsection{Culturalization and Racialization of Muslims in the US}

The first trend that is enhancing the resemblance between the US and European context regards changes in the perception and framing of Muslims in the North American public discourse. In the US, the Hungtinonian view of Islam as the enemy of the West has long been framed in securitarian terms. As illustrated above, the related perception of threat has only marginally been referred to Muslim migrants living in the US. Rather, it has been attributed to Islam as an external player in contemporary geopolitics and as a danger within the sphere of international relations. In Europe, by contrast, Muslim migrants have traditionally undergone processes of cultural racialization, by which they have been interiorized not so much on the basis of a biological characteristic, but rather of their anti-modern culture and religiosity (Modood, 2018; Alba, Foner, 2015). Since the beginning of the 2000s, however, this difference between the European and the North American contexts has been gradually disappearing, with Muslim migrants living in the US being progressively racialized and seen as inherently culturally inferior to the mainstream, white society.

Mostly following the 9/11/2001 terrorist attacks, this demonization of American Muslims, previously limited to fringes of public opinion, has reached wide layers of society. This has normalized anti-Muslim narrative and led to the setup of structured, well-funded Islamophobic movements. Several authors highlight how, within the framework of the war on terror, anti-Shari'a legislations were proposed and enacted by many American States: such Islamophobic politics has fueled, across the country, anti-Muslim attitudes, generating discrimination of Muslim migrants on the basis of religious/physical signifiers (Nagel, 2016; Garner, Selod, 2015; Cainkar, 2009) - which most detrimentally affects Muslim communities that are exposed to intersectional discrimination, such as Black Muslims living in impoverished urban areas (Beydoun, 2017). Particularly, Trump's anti-Muslim rhetoric and policies -such as the so-called "Muslim ban" and his proposal to create a Muslim registry- had a decisive role in these ongoing processes (Yukich, 2018), especially because this rhetoric was skillfully supported and amplified by the alt-right movement, through a website such as Breitbart (Lean, 2017).

Hence, even in such a "religion-friendly" context as the US, migrants' religiosity has started to be unwelcome and seen, like in Europe, as a barrier to 
pacific coexistence when the social construction of Islam as a diametrically different cultural reality has come into play. This trend has attracted the attention of US social scientists, who have underlined the utility of concepts such as racism and racialization for understanding Islamophobia in the US and have highlighted the need to deepen, through fieldwork-based studies, the impact of anti-Muslim sentiment, rhetoric, and behaviors on the everyday life of American Muslims with migratory background (Husain, Howard, 2016; Garner, Selod, 2015; Cainkar, 2009).

Interestingly, literature also highlights the dialectic relationship between islamophobia and general anti-migrant attitudes in the US, and reveals the impact of anti-Muslim politics on anti-refugee sentiment across the country (Nagel, 2016). For instance, Islamophobia and the fear of terrorism, fed by the attacks in Paris and the mass shootings in San Bernardino, California (December 2015), or in Orlando, Florida (June 2016), had a meaningful role in fueling the support for the strong republican opposition to the resettlement plan for 10,000 refugees from Syria eventually carried out by the Obama administration in 2016 (Nagel, 2016). Such an interrelation between anti-Islamic and antirefugee sentiment, along with the intensifying racialization of Muslim migrants, represent a further tendency that makes the US context increasingly similar to the European one, where reactions of refusal towards the recentlyarrived refugees and migrants are also based on their religious affiliation, as we will show in $\$ 3.2$. This constitutes a significant shift in a context where religion, as explained in $\S 1$, hardly represented a serious basis of contention in the processes of incorporation of newcomers in North America in the past.

However, in the US, this view of migrants as problematic and unwelcome due to their religious affiliation gains center stage only in the case of Muslim migrants: indeed, the present polemics concerning irregular migration flows from Latin America through the border with Mexico do not contemplate their religion at all. This does not mean that, since they are mostly Christians, or in any case non-Muslims, they are easily welcomed. However, the social and cultural distance between them and mainstream society is constructed on elements other than religious affiliations.

In sum, in the US migrants' religion is perceived as problematic for the cohesion of American society only when it comes to Muslims. This has happened only recently, and it is hard to foresee what effect this will have on US social sciences. What is certain, as has amply been illustrated in $\S 1$, is that North American social research, having concentrated on faiths and on communities different than the Islamic one for a long time, could focus on the integrative aspects of religion. This led to establishing a proper tradition of research in this 
field that highlighted the positive role played by religion in migrant integration processes.

On the other side of the pond, migrants' religion has long been considered exclusively in negative terms, because it has always been equated with Islam (although this does not reflect the reality of figures, as shown in \$2). The negative consideration of this religion implied that research had to overcome the widespread attitude of considering religion as an obstacle to integration, but, in doing so, it ended up unwittingly reinforcing or legitimizing this preliminary assumption, even if it aimed at deconstructing it, for the simple reason that it constituted its starting point.

This comparison leads us to underline, once again, that it is precisely the social construction of Islam as the monolithic, paradigmatic Other the filter that has made it difficult for research to avoid the conundrum of the circular and mirroring dynamics between public perceptions and social investigation. It may be safe to argue that, when the "threatening", "radically different" Other is out of the focus of research, the potential beneficial contributions of religion to social life and the inclusion of migrants can be investigated much more easily and more fruitfully. When Islam is not the object of research, approaches to the study of religion yield research results that seem to provide a more complete picture of the often-beneficial role played by religion in migrants' processes of settlement, which may possibly go unnoticed when research focuses on "the problematic religion".

\section{2 \\ Migrant Religion as a Category of Practice in Integration Measures Across Europe: a New Attitude?}

The other shift that, in our view, is gradually making similarities appear between the North American and the European context concerns subtle changes occurring in the perspective generally adopted in Europe in looking at the "religion and integration" nexus. This development-with its controversial aspects and implications- is the object of the conclusive pages of the present chapter.

As discussed by a number of authors, the traditional negative consideration of Islam and the perceived difficult inclusion of Muslim migrants in society that, as described above, developed in the European public sphere led to treating religion -read, Islam- as a category on its own of migrant integration policies. Through this process, "Islam", and, subsequently "religion", have been framed as pivotal policy areas in the steering of migrant integration (as hinted at also in Chapter 3 of this volume). This has typically concerned religionrelated measures aimed at meeting the claims of Muslim minorities and the institutional establishment of their religion -mosque-building, halal butchery, 
or teaching of religion in schools... (Brunn, 2012; Joppke, 2009). Such measures, usually very contentious, have been generally framed so as to primarily meet aims of control and of assimilation. In line with a view that has uniformly cast religion as an obstacle to integration across European countries, it is not surprising that the inclusion of "religion" within the realm of migrant integration policies bears the mark of the centuries-old consideration of religion as a potentially dangerous "force" to be "tamed".

Whilst in the past migrants from Muslim-majority countries were mostly identified through their legal status (e.g. foreigners, third-country nationals, guest-workers), or through their nationalities, this has progressively shifted to "Muslim" as a religious group (Mattes, 2018; Yllmaz, 2016; Brubaker, 2013; Nielsen, 2013; Bleich, 2009). Needless to say, the choice of policy categories is tightly interconnected with problem formulation and has a decisive influence on the proposed measures and their implications. In this case, the underlying assumption is that, in order to reach integration goals, the religion professed by migrants becomes as relevant as -or even more meaningful than- for instance, socio-economic aspects or ethnic-national ties. This approach is marked by meaningful criticalities: if the very concept of migrant integration assumes that some "others" are to be integrated within the supposedly uniform nation-State, then a political practice that targets "Muslims" categorizes these "others" based on their religious belonging and risks reinforcing an exclusionary effect, linked to this specific component of their identity, conceived of as a collective attribute (Mattes, 2018; Korteweg, Yurdakul, 2009).

However, recent developments that occurred in Europe in the mid-2010s triggered some partial changes in the public policies or in the initiatives developed by a number of European countries with reference to the treatment of migrant religion. As is known, Western European countries have been the target of deadly and vast jihadist attacks between 2014 and 2017. The fear of Islamist terrorism could not but sharpen the perceptions of social and cultural distance from Islam and Muslim migrants. A further circumstance took time in the same unfortunate period - i.e. the so-called "refugee crisis". The growing number of people seeking asylum in Europe has caused widespread public anxieties, with refugees' religion frequently becoming the main focus of these concerns (Buber-Ennser et al., 2018; Zanfrini, 2019). This was clearly reflected by the reaction of the self-defined "Visegrad group" (Poland, Slovakia, Czech Republic, Hungary) to the policy of redistribution of migrants among EU Member States designed by the European Commission. These Central and Eastern European countries explicitly and repeatedly expressed their refusal to accommodate quotas of migrants, on the grounds that their religious affiliation, mostly Islamic, would pose a threat to their societies. 
In this case, the difference that was stressed was not so much along the fault line dividing "the secular us" and "the backwardly religious them"; rather, what was highlighted was the Christian identity of the receiving countries, put in danger by the arrival of Muslim asylum seekers (Krotofil, Motak, 2018; Brubaker, 2017). This adds a problematic shade to the already negative consideration of the relationship between religion and integration spread in the European culture. Furthermore, it offers the opportunity to develop a provocative reflection, as one might reasonably ask whether these asylum seekers would have been welcomed, had they been Christian.

What is certain, in any case, is that in Europe jihadist violence and the socalled "refugee crisis" had the indirect consequence of renewing the role of religion as a symbolic boundary, that is, as a category marking perceptions of self and otherness (Krotofil, Motak, 2018). The occurrence of the two phenomena at the same point in time further reinforced the tendency to identify migrants with Muslims and Muslims with migrants, in conjunction with the assumption that Islam and terrorism are inextricably interwoven (Pickel, 2018) or that "jihadism" represents the "quintessence" of "real Islam" (Geisser, 2015). This distortive overlapping, defined by Schiffauer (2007) as a "muslimization of migrants", expands the perceived social and cultural distance between "us" and "them". Whilst invisibilizing both natives of Islamic faith and migrants professing other credos -despite their conspicuous presence- this served the logic of promoting a Christian identity narrative especially in Eastern European countries - which worked as a marker of "internal" unity (Mattes, 2017; Mavelli, Wilson, 2016; Johansen, Spielhaus, 2012). Indeed, in the context of a social reality characterized by plurality and complexity, religious identity, when taken in its cultural contents more than in its strictly spiritual meanings, risks assuming a reactive connotation (Brubaker, 2017), being utilized to affirm "reassuring", essentialized differences between an "ingroup" and an "outgroup" (see Chapter 3).

At the level of policy-making, this renewed focus on religious identities translated into a renovated interest in transforming religion into a "cornerstone" of integration measures - however, with some ambivalent attitudes. Certainly, the attempt to "control" and "contain" religion continues to significantly characterize many of these measures. For instance, it is through the development of "Muslim" as a category of integration that the prevention of radicalization has become a primary objective of integration policies. One of the most famous examples in these domains is represented by the approach developed by the UK government, with its "Prevent" strategy - a national plan aimed at countering jihadist radicalization, which has explicitly targeted "Muslims". Many observers have highlighted the strongly stigmatizing effects 
of this strategy: by targeting leaders of Muslim communities, or by encouraging school teachers and healthcare officers to report about possible "suspect" cases of radicalization, this caused Muslims to be increasingly viewed by the public opinion as a homogeneously dangerous, suspect group, thus eroding trust and social cohesion (Qureshi, 2017; Open Society Justice Initiative, 2016). In this sense, the exclusionary framing of the link between religion and integration policies continues a well-established pattern in policy-making, whereby migrant integration policies feature "migration-security" and "religionsecurity" nexuses, aimed at addressing the perceived security threat represented by Muslim migrants (Mattes, 2018). Such a political agenda keeps serving the interests of political parties that rely on the social construction of juxtaposed "us" and "them" identities for gaining electoral consensus.

At the same time, however, the potentials of religion for facilitating migrants' social inclusion start to be taken into account across European countries. The involvement of faith-based organizations is increasingly acknowledged as a fruitful way for promoting integration, as religious communities are recognized in their function of single point of contact for State actors, and their organizational structure is seen as a strategic basis for the implementation of integration measures (Mattes, 2018). For instance, in the National Integration Plan for Beneficiaries of International Protection launched by the Italian Government in 2017, ${ }^{6}$ interreligious dialogue is counted as one of the four pillars for the promotion of integration. In Germany, the "German Islam Conference" has been explicitly conceived as an integration device: while at the beginning it can be said to have served more the interests of the State in "domesticating" Islam, its efforts have increasingly concerned Muslim's needs, with a recognition of the welfare provided by German Muslims communities e.g. in childhood and elderly care. Moreover, the Conference has also officially acknowledged and supported the role played by Muslim organizations in the provision of aid and assistance to the refugees who arrived in Germany at the peak of the "refugee crisis" in $2015^{7}$ (Chbib, 2016).

Again, these approaches may be problematic, as they continue to apply a "group" label and essentializing its religious dimension, while risking subduing

6 See the version of the Plan translated into English: http://www.interno.govit/sites/default/ files/piano_nazionale_integrazione_eng.pdf (last accessed: 05 July 2019).

7 See https://www.bmi.bund.de/EN/topics/community-and-integration/german-islamconference/german-islam-conference-node.html; https://www.deutsche-islam-konferenz. de/SharedDocs/Anlagen/DE/Ergebnisse-Empfehlungen/20170314-la-3-umsetzungsberichtwohlfahrt.pdf?_blob=publicationFile\&v=6; https://www.an-nusrat.de/suem-dik/ (last accessed: 05 July 2019). 
religion to control aims (Stålsett, 2018; Tezcan, 2012). Nonetheless, these developments represent a meaningful innovation in the European landscape and in its perspective on the link between religion and integration, as they may open up a new field in integration policies, possibly creating further, novel opportunities which, if properly harnessed, may fruitfully bring about positive consequences. For instance, while the prevention of radicalization has more often the exclusionary effects described above, it also represented the starting point for experiences of cooperation between State institutions, practitioners and religious leaders, as documented in the collection of practices constantly updated by the Radicalization Awareness Network (RAN), coordinated by the European Commission (RAN, 2017; 2016).

Other interesting cases, in this regard, are offered by Italy and Denmark. In Italy, the State signed an agreement with the largest federation of Islamic associations (UCOII - Unione Comunità Islamiche Italiane) giving the possibility to Islamic religious guides -four women and four men- to access eight prisons in order to provide spiritual assistance and religious instruction to Muslim detainees (Angeletti, 2018), with the aim of countering the possible spread of the "jihadist" message in jails - i.e. contexts that have been identified as breeding grounds for radicalization phenomena across European countries. In Denmark, the model for preventing radicalization and for reintegrating so-called returnees (i.e. individuals who had joined the jihadist insurgency in Syria and have returned to their home country), developed by the city of Aarhus, envisages a rehabilitation and mentoring program involving family networks, social workers, teachers and religious communities and places of worship (Bertelsen, 2015). The person who was actively involved in jihadist networks, or is likely to get involved, is assigned a mentor, who engages in sustained dialogue efforts also of religious and theological nature. ${ }^{8}$ It is out of the scope of the present contribution to assess the premises and the effects of these measures from the point of view of the prevention of radicalization. What is of great interest, for the purposes of this analysis, is that, in these practices, precisely religiouscultural proximity gets valued, with religion being considered as an ally in promoting social cohesion, rather than as an obstacle.

8 See Hanna Rosin, "How A Danish Town Helped Young Muslims Turn Away From ISIs", NPR, 15 July 2016 (https://www.npr.org/sections/health-shots/2016/07/15/485900076/how-a-dan-

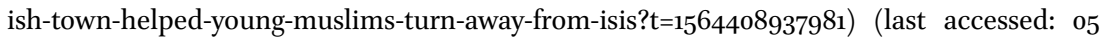
July 2019); Tim Mansel, "How I was de-radicalized”, ввС, 2 July 2015, (https://www.bbc.com/ news/magazine-33344898) (last accessed: 05 July 2019); David Crouch, "A way home for jihadis: Denmark's radical appraoch to Islamic extremism", The Guardian, 23 February 2015 (https://www.theguardian.com/world/2015/feb/23/home-jihadi-denmark-radical-islamicextremism-aarhus-model-scandinavia) (last accessed: 05 July 2019). 
That religion is gradually being framed as a resource to tap into for fostering integration and inclusion is also demonstrated by an array of pragmatic, promising initiatives and practices realized by local administrations and civil society, which often seem to be animated by a genuine belief in the role of religious organizations as fully-fledged actors able to play a potentially meaningful and positive role in the integration of migrants. For instance, several civil society organizations promoting migrants' social inclusion are putting in place multidimensional interventions considering religion as a key factor to properly consider. For instance, the KAICIID ${ }^{9}$ organization for interreligious and intercultural dialogue, which gathers high-level representatives from major world religions, has initiated a "Program for the social inclusion of people seeking refuge in Europe", with the explicit aim of bringing together representatives from faith-based and secular organizations at various levels (local, national, and international), for providing capacity-building for the integration of people seeking refuge and migrants in Europe ${ }^{10}$ based on the assumption that "because all mainstream religious traditions promote inclusion and care for poor or marginalized people, integration provides a fantastic opportunity for coordinated interreligious cooperation". So far, this initiative has concretely resulted in a pilot project carried out in Vienna, in which dialogue features as "key" to integration: with the aid of four dialogue facilitators having a migrant background (Syria and Afghanistan), thirteen dialogue sessions with refugees have been organized between 2018 and 2019, in order to help refugees "deepen their understanding of Austrian systems, services, and culture". Moreover, the initiative is creating a Network with other European grassroots organizations for promoting interreligious dialogue for social inclusion, and has produced a Toolkit for refugee integration. ${ }^{11}$

This kind of approach has also been encouraged by EU institutions through their soft-steering instruments, and has been adopted by international organizations or by third-sector entities operating in Europe. For instance, the International Organisation for Migration (IOM) implemented several projects in Germany: i.e. the "Integration: A Multi-faith Approach" (IAMA) project, the "Dialogue for Integration: Engaging Religious Communities" (DIRECT) project,

$9 \quad$ KAICIID stands for "King Abdullah Bin Abdulaziz International Centre for Interreligious and Intercultural Dialogue" - https://www.kaiciid.org/who-we-are (last accessed: 05 July 2019).

10 See https://www.kaiciid.org/what-we-do/programme-social-inclusion-people-seekingrefuge-europe and https://www.kaiciid.org/news-events/news/network-dialogue-work shop-takes-place-bologna-defines-way-forward-and-membership (last accessed: 5 July 2019).

11 See https://www.kaiciid.org/publications-resources (last accessed: 05 July 2019). 
and the "Pilot multi-faith and interfaith fora for religious leaders of third country migrant communities" (REKORD) project. They were co-funded by the European Commission (European Fund for Integration) and supported by the German Federal Office for Migration and Refugees (BAMF), with the aim of enhancing the role of religious communities in the integration process.

These recent trends are likely to have implications on the conceptualization of the integration and religion nexus, that could be fruitfully explored through research. More broadly, the new tendency featuring both civil society and EU and national-level institutions to conceive religion as a key resource in integration offers scholars a rich ground of investigation. In fact, the linkage between religion and integration has started to be the subject of some recent contributions by European researchers, who, more in the vein of the American tradition, analyze the potentials of religion and of ғво for promoting social inclusion processes, thus deviating from the European tradition, which tends to look at religion as an obstacle to social inclusion (Khallouk, 2018; Andrej, 2018; Ager, Ager, 2016; Mavelli, Wilson, 2016; Snyder, 2012).

One could argue that, through the fears generated by the Islamist terror attacks and the refugee crisis, European societies have (re)discovered religion as a meaningful ingredient in social life: while, on the one hand, this continues to be framed as a dividing line, drawing on its symbolism to justify "fortification" processes (Schmiedel, Smith, 2018), there has also been a re-evaluation of religion as a dimension of migrants' life, which should not be neglected for the purpose of facilitating their process of settlement.

The attention recently expressed by civil society and some State's actors for religion as a dimension of migrants' integration undeniably offers rich and promising investigation paths to researchers - as some contributions comprised in this volume will start to explore. Studying the plurality of migrants' religion with a view to analyzing how the dimension of faith interacts with integration processes certainly represents an innovative perspective in the landscape of European social sciences. In the light of the considerations developed in this chapter, we hope that research on these themes will be able to adopt, as compared to the past, a more neutral approach to the study of religion -and certainly of Islam- in order not to run the risk of beginning investigation endeavors by having to deconstruct religion as an obstacle to social inclusion. 